\title{
NUTRICIÓN
}

\section{Patrones de ingesta de líquidos: un estudio epidemiológico en niños y adolescentes escolarizados de Paraguay}

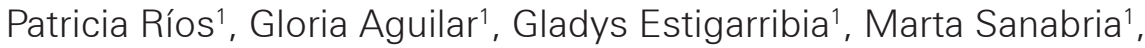 \\ Gabriela Sanabria', Anibal Kawabata', Sergio Muñoz', Rubens \\ Ferferbaum ${ }^{1}$
}

\begin{abstract}
Resumen
Introducción: Existe un aumento significativo en la ingesta de energía entre los niños y adolescentes a partir del consumo frecuente de azúcares añadidos a los alimentos procesados y bebidas. En una revisión sistemática de la literatura se encontró que el consumo regular de calorías de azúcar en forma líquida es responsable de la ganancia de peso corporal debido a la baja saciedad y el alto contenido de azúcar. En el Paraguay no se han evaluado los patrones de consumo de bebidas en niños/niñas y adolescentes en cuanto volumen y la calidad. Para abordar la obesidad y sus posibles causas desde un punto de vista científico es preciso obtener información sobre el consumo tanto en cantidad como en calidad de bebidas por los niños/niñas y adolescentes que ayudara a contar con evidencia para implementar políticas públicas que promuevan las condiciones necesarias para una vida saludable y eliminación de ambientes obesogénicos.
\end{abstract}

Objetivo: Determinar el volumen de consumo y la media de energía diaria por cada categoría de líquidos en niños/niñas y adolescentes en Asunción, Central y Caaguazú.

Metodología: Estudio observacional, descriptivo, de casos y controles anidados. Muestreo probabilístico, multietápico, estratificado por edad (7 a 19 años) y por conglomerados (escuelas de Asunción, Central y Caaguazú) Tamaño muestral: 2352 sujetos. Se realizó recordatorio de 24 hs de muestras repetidas, mediciones de peso y talla según los estándares internacionales (OMS2007). Requerimientos de energía FAO/ONU 2004 INAN. MSP y BS. Análisis ANOVA y T Test. Significancia: $p<0,05$.

Resultados: Ingresaron al estudio 2352 sujetos (7 a 19 años), de los cuales el 28,3\% (642) fueron menores de 7 a 10 años, el 54,9\% (1245) de 10 a 14 años y el 16,8\% (379) de 15 a 19 años. En cuanto al volumen de líquidos consumidos en promedio ( $\mathrm{ml} / \mathrm{día}$ ), por categoría de líquido y grupo de edades, el agua en menores de 10 años en promedio fue $750+486$ de 10 a 13 años $940+617$ y 14

1. Instituto Regional de Investigación en Salud "Kaneo Shibata", Facultad de Ciencias de la Salud, Universidad Nacional de Caaguazú, Paraguay.

E-mail: pattyriosmujica@hotmail

DOI: $10.26885 /$ rcei.foro.2017.102 
años y más $1175+763$ con una p 0.00 , leche y derivados en menores de 10 años en promedio fue $395+165$ de 10 a 13 años $383+365$ y 19 años y más $865+824$ con una p 0.05, infusiones en menores de 10 años en promedio fue $200+102$ de 10 a 13 años $940+617$ y 14 años y más $1175+763$ con una p 0.00 , Jugos naturales, en menores de 10 años en promedio fue $438+252$ de 10 a 13 años $521+329$ y 14 años y más $537+299$ con una p 0.01, bebidas artificiales en menores de 10 años en promedio fue $354+226$ de 10 a 13 años $400+251$ y 14 años y más $490+323$ con una p 0.01, Néctar, en menores de 10 años en promedio fue $282+167$ de 10 a 13 años $305+168$ y 14 años y más $405+389$ con una p 0.05 , Bebidas carbonatadas en menores de 10 años en promedio fue $355+283$ de 10 a 13 años $449+326$ y 14 años y más 445 SD +347 con una p 0.01. El promedio de calorías de líquidos consumidos por categoría de líquido y grupo de edades fue, en leche y derivados, en menores de 10 años en promedio fue $301+123$ de 10 a 13 años $289+134$ y 14 años y más $275+155$ con una p 0.00, infusiones, en menores de 10 años en promedio fue $57+60$ de 10 a 13 años $61+57$ y 19 años y más $58+65$ con una $p$ 0.45 , jugos naturales, en menores de 10 años en promedio fue $198+118$ de 10 a 13 años $233+144$ y 14 años y más $239+134$ con una $p 0.00$, bebidas artificiales, en menores de 10 años en promedio fue $103+71$ de 10 a 13 años $95+71$ y 14 años y más $103+104$ con una p 0.22, néctar en menores de 10 años en promedio fue 132 + 70 de 10 a 13 años 149 + 99 y 14 años y más $182+193$ con una p 0.01, bebidas carbonatadas, en menores de 10 años en promedio fue $180+105$ de 10 a 13 años $211+129$ y 14 años y más $233+135$ con una p 0.01 .

Conclusión: El consumo promedio diario de agua, infusiones, jugos naturales, bebidas artificiales, bebidas carbonatadas y néctar se incrementó con la edad. El consumo promedio de leche y derivados disminuyó con la edad. En relación al promedio de calorías consumidas por categoría de líquidos, la leche y derivados fueron los mayores contribuyentes de energía suministrada por los líquidos, con una disminución de la energía aportada a medida que incrementaba la edad. La siguiente categoría de líquidos en aporte de energía, fue la de los jugos naturales, con un incremento de aporte a medida que aumento la edad. Las bebidas carbonatadas se constituyeron en el tercer grupo de categoría con un aporte de energía que se incrementó conforme aumentaba la edad.

Palabras clave: obesidad, niños, ingesta de líquidos.

\section{Referencias}

Feferbaum, R., de Abreu, L. \& Leone, C. (2012). Fluido intake pattens: an epidemiological study among children and adolescents in Brazil. Public Health, 12(1005), 1-7.

Fernández, J., Iglesia, I, Ferreira, C. \& Babio, N. (2014). Nutrición Hospitalaria. Grupo Aula Médica, 29, 1163-1170.

Aparicio, R. \& Rivas, M. (2013). Evidencias en Pediatría. Toma de decisiones clínicas basadas en las mejores pruebas científicas, 9(23), 1-4. 